\title{
Application of Value for Money in Engineering Consultation in the Whole Process of Construction Project
}

\author{
Junjie Qiao \\ Tianjin University of Technology, Tianjin, 300384, China. \\ 727247738@qq.com
}

\begin{abstract}
With the rise of PPP, value for money has been well known in recent years. Its original intention is: in order to satisfy the goal of maximizing the value of the project, according to the value engineering $V=F / C$ model, the implementation plan of each stage of the project $t$ is continuously improved, and ultimately the investment goal is to achieve the highest cost performance ratio; this paper finds out the key factors of each stage of the construction project through the application and management of value for money, and also finds out the possible increase in the project price. Value and the tools to reduce the cost of the project, with a view to the development of value-for-money theory and practice of construction projects.
\end{abstract}

Keywords: value for money, LCC, VM, constructability, Operability.

\section{Introduction}

Value for money evaluation is a core system of the current government and social cooperation (PPP) policy in China, and it is the decision-making basis for judging whether to adopt the PPP model. In 1988, R. Glendin-ning analyzed the core meaning of "value for money" in public expenditure. Subsequently, theorists began to study the qualitative and quantitative criteria for measuring "value for money" in order to better guide practice. In recent years, the British Treasury has proposed that "value for money is the best combination of cost and quality over the life cycle of a product or service to meet the needs of users, and value for money is not the lowest tender price." This definition has been imitated by many countries.

Now the engineering cost consulting enterprises have set up the goal and mission of increasing the value for the project. The standard of value added for the project is to pursue the highest cost performance in order to achieve value for money. Value engineering, life cycle cost management, constructability analysis and operability analysis are the means to add value to the project. It is advocated that value-added analysis should be carried out at every stage of construction and strive for value for money.

\section{2. "Value for Money" Application Tool}

\subsection{Tool 1: Life Cycle Cost Management (LCC).}

Taking the Olympic Stadium in Tianjin as an example, the roof truss adopts steel truss cantilevered structure. The roof truss is landed like water drops. The design of "Water Drop" fully considers the cost reduction of LCC, and "Water Drop" considers the management problems after the completion of the design. In addition to the competition room, 34,000 feet of room are used for sports operation income. This is the operation of merging into the design, to cultivate the field, to really form a landscape, equipment can be trained, and try to make water drop into shape. It is a mass entertainment base, place and business center with space available. The idea of LCC is to take the whole life cycle as the perspective, focusing on the pre-planning and investment control, pay attention to the coordination of operation and maintenance costs and construction and operation organization, so that the project "value for money".

\subsection{Tool 2: Value Management (VM).}

Known as value analysis, is a modern management science combining technology with economy. It is an organized and creative activity that focuses on functional analysis and strives to reliably 
achieve the necessary functions with the lowest life cycle cost. Value engineering is used to optimize the design plan to achieve value enhancement.

The goal of value engineering is to improve the value of products. The term "value" here refers to the ratio of the function an object has to the total cost of acquiring that function, which can be expressed in a formula: value $(\mathrm{V})=$ function $(\mathrm{F}) /$ cost $(\mathrm{C})$. Like value engineering, the concept of value for money is also pursuing higher value. Value for money should be the goal of optimization and improvement of all projects (not just government projects). This idea of continuous improvement should be embodied in the project initiation, planning, design, construction, operation and other stages. That is to say, in the whole process of Engineering consultation, we should also learn how to use value for money in the consultant practice.

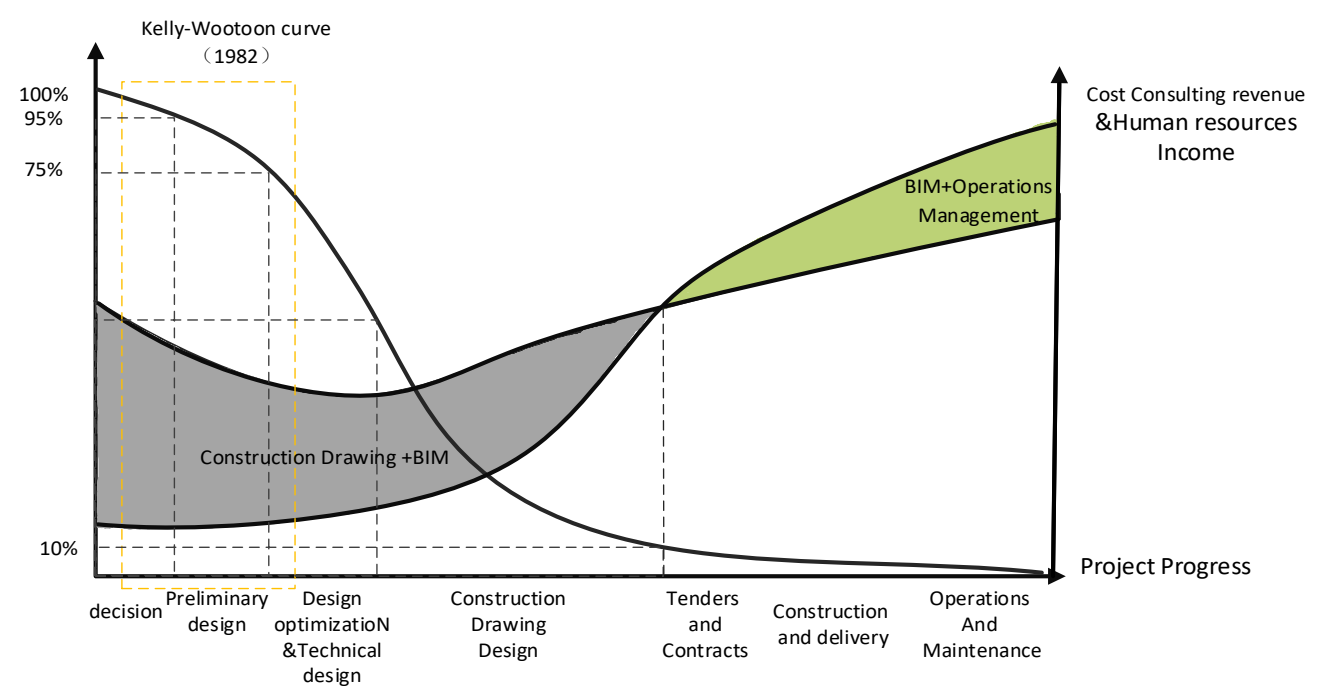

Fig. 1 Kelly's curve

Kelly's (1982) study found that $80 \%$ of a project's cost had already been determined at the design stage, so follow-up control could only affect the remaining 20\%; Wootoon (1982) thought that the part of the total project's cost that could be directly controlled by the site accounted for about $6 \%$ $20 \%$. The study concluded that:

(1) Design must consider the short-term and long-term requirements, forward integration: strengthen planning and design optimization + BIM, improve the fineness of investment control; later integration: BIM + operation and maintenance management, optimization of operation and maintenance resources input cost engineers should focus on the entire project life cycle, forwardbackward, stable intermediate, forward integration of late information to realize project increment;

(2) The design must take account of the construction and use, and consider the cost of the whole life cycle of the project.

(3) The design scheme must deal with the relationship between economic rationality and technological advancement, and within the limits of funds, improve the project function level as far as possible.

Attention should be paid to the value-added effort in the early stage is the most effective, the whole process of engineering consulting enterprises should consciously in the early stage of the project allocation of more, especially to strive for the early planning services of the project. The whole process project management runs through the whole life cycle of project planning, implementation (design, contracting, construction, completion) and operation. The idea of dynamic control of the whole process cost management is applied to control the project cost. The emphasis will be put on the cost management in the project proposal stage, the cost management in the design stage and the invitation and investment in the implementation stage. Site management, construction site management and project management during use. 


\subsection{Tool 3: Constructability.}

Constructability is generally used in the design stage as the third way to control the cost of the project and increase the "value for money" of the project. The purpose of constructability research is to achieve the goal of the project better. It requires the construction personnel to participate in the planning, design, procurement and other phases of the project as soon as possible. The construction experience and knowledge are applied to the whole process of the implementation of large projects, avoiding the problems caused by the separation of traditional design and construction. At the stage of project concept planning, constructability research will be carried out so that experienced construction experts can participate in the implementation of the project as soon as possible, make full use of their construction experience, provide information for early decision-making, and properly influence owners, planners, designers and suppliers of materials and equipment, so as to maximize the production. The benefits of the project shorten the duration of the project, improve the overall quality, operability, maintainability and reliability of use have improved, and reduce the project life cycle cost.

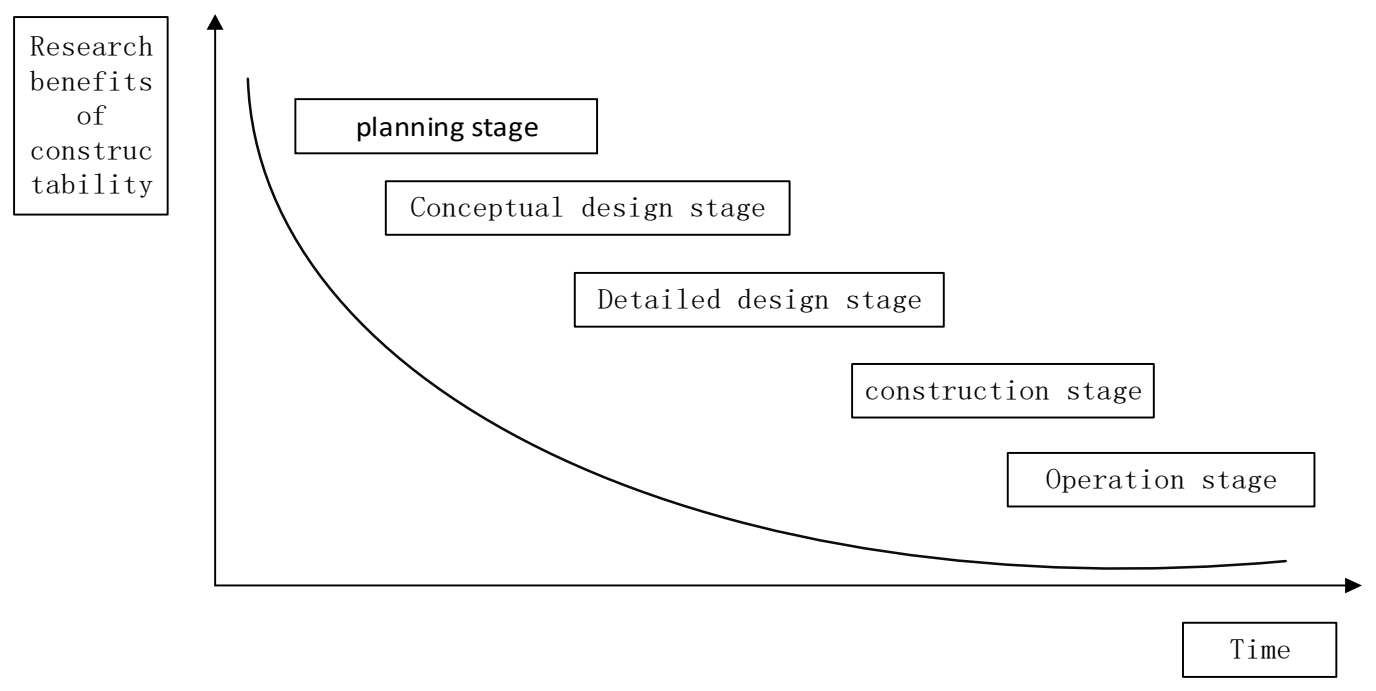

Fig. 2 Research benefits of constructability

The study of constructability mainly emphasizes the systematic study in the whole process of project implementation, giving full play to the role of experience and knowledge of construction personnel. That is, construction research should be part of the overall planning of the project implementation, starting from the owner's idea of project requirements, and continuing throughout the implementation cycle of the project until the completion and commissioning of the entire project.

Constructability provides an opportunity to achieve higher efficiency from construction projects, resulting in lower costs, shorter construction periods or higher quality. Research on constructability is the embodiment of life cycle cost thought and the key to "value for money". Consider how the project will be disposed of at the end of its life cycle, minimizing its resource requirements. How should the components of the project be reused or how to minimize the consumption of nonrenewable resources? Constructability is to evaluate the design of a project so that it is compatible with the standards and constraints and maximizes the benefits while minimizing resource consumption throughout the life cycle of the project.

\subsection{Tool 4: Operability.}

Operability By borrowing the definition of "feasibility" analysis, this paper investigates the main contents and supporting conditions of the whole process project, such as market demand, resource supply, construction scale, technological route, equipment selection, environmental impact, fund raising, profitability, etc. This paper analyzes and compares the financial, economic and social 
environmental impacts that may be achieved after the completion of the project, and predicts whether the project is worth investing, how to carry out construction consultation and whether it conforms to the operation of the whole process of Engineering consultation, thus providing a comprehensive basis for project decision-making. The method of system analysis is used to form an engineering plan that meets the needs of the owners and optimizes the technical route. Operability should be predictable, impartial, reliable, scientific and comprehensive, and "value for money" embodied in the whole process of Engineering consultation.

Due to the unclear division of responsibilities between project construction and project operation, the whole process engineering consulting organization can effectively achieve the expected benefits in project management only by clarifying the responsibilities of different roles. Therefore, in order to ensure the successful implementation and management of the project, it is necessary to clarify the allocation of responsibilities, powers and benefits of the whole process engineering consultancy. In the process of responsibility allocation, all stakeholders who have an impact on project income should be considered to ensure the smooth implementation of the task of change. Comparing with project management, the whole process of project management is not only a mechanical synthesis of different project management, but also a comprehensive coordination management process of project, strategy and organizational activities. Whole process engineering management integrates project management knowledge, technology, tools and skills to meet or even exceed the expected objectives of the organization's investment strategy.

In fact, the operability analysis of a project is based on the feasibility analysis and adds the "answer" of time - the "expansion" of the whole life cycle and space - to the key points of each project stage, and the chief consultant in the whole process engineering consultancy organization needs to shift his vision from "local variables" to "whole". Function, from "current" to "life cycle", and the current development direction of construction projects should also be changed from local optimization to the whole life cycle of the project optimization design. Operational research is the key to scientific decision-making and alternative selection of the project, but also one of the footholds of "value for money". This means that the whole process of the project in the early stage of construction must go through the operability study, so as to ensure that "value for money" in the project "throughout".

\section{Summary}

The key to value-for-money application is to reduce unnecessary costs and maintain or improve existing functions through the application of LCC, VM, constructability and operability tools, providing opportunities to enhance project value. Therefore, value for money application management can find out the key factors of the project, and also find out the possible ways to improve the project value and reduce the project cost. It provides a team-oriented approach, so that the whole process of engineering consulting team to establish a sense of pioneering and innovative, to absorb the knowledge of new technology, new materials, new technology. Thus, the market competitiveness of enterprises is strengthened.

"Value for money" should be the goal of all projects, initially used in public procurement audits, with $3 \mathrm{E}$ as the core, namely, economy, efficiency, and subsequent use of the focus should be on the pursuit of value rather than cost. If the leaders of engineering cost consulting enterprises only emphasize value-added and do not know the specific plan, they will lose their direction. Therefore, we should study value engineering to really use value for money in consulting practice, so that value for money throughout the whole process of engineering consulting management.

\section{References}

[1]. Peng W, Cui Q, Lu Y, et al. Achieving Value for Money: An Analytic Review of Studies on Public-Private Partnerships C// Construction Research Congress.

[2]. Yilin YIN, Project cost management, Machinery Industry Press,2018.5, Preface. 
[3]. Sun Jide, Liao Qianshao. Study on the constructability of construction project [J]. Journal of Tongji University (Natural Science Edition), 2002, 30 (8): 1001-1004.

[4]. Cao Fuguo. The connotation and development of the theory of value for money [J]. Chinese government procurement, 2016 (7): 34-36.

[5]. Li Liangqun. Analysis of the application of value engineering in China's construction industry [J]. Technology economy, 2004 (10): 60-62. 